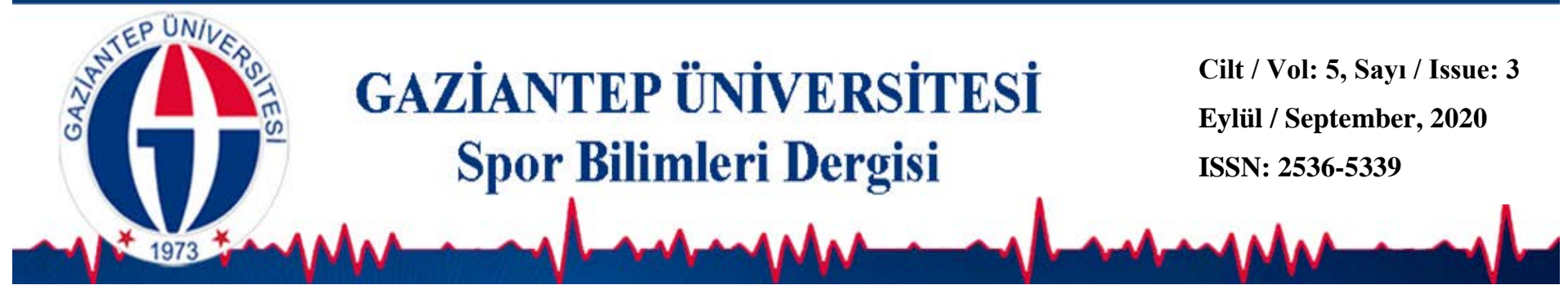

\title{
Implementation of Plyometric Exercises to Improve Throwing Velocity of Male Youth Baseball Players
}

\author{
Dinçer CÜRE ${ }^{1 *}$ David GRIFFITHS ${ }^{2}$ (D) Anthony J. STERLACE ${ }^{3}$ (D) \\ ${ }^{1}$ Podotürk Ayak Sağlığı Merkezi, Aydın, TURKEY \\ ${ }^{2}$ Griffiths Sports Physiotherapy, Niagara Falls, Ontario, CANADA \\ ${ }^{3}$ Brierwood Physical Therapy, PC, Hamburg, NewYork, USA
}

DOI: $10.31680 /$ gaunjss.764381

Orijinal Makale / Original Article

Gelis Tarihi / Received: 10.07.2020
Kabul Tarihi / Accepted: 10.09.2020

\begin{abstract}
The purpose of this study was to examine the effects of a six-week upper-extremity plyometric exercise program on throwing velocity of male youth baseball players. This study utilized a quasi-experimental design in which comparisons were made between an upper-extremity plyometric group and a comparison group. 12 players were randomly recruited from two select level teams (12-15 each team) as a sample of convenience. Of those 12 players, 6 were randomly assigned to an experimental group and the other 6 were assigned to a comparison group. The experimental group participated in a supervised upper-extremity plyometric strength training program two times per week for 6 weeks, as well as a parent supervised home exercise program to be performed at home once per week. The comparison group completed their usual practice routine. All statistical analyses were conducted using SPSS (version 16.0; Inc., Chicago IL). And independent t-test, a Mann-Whitney test, and two Wilcoxon signed ranks tests were utilized to attempt to identify within, and between, group differences for the variables that were studied. After 6 weeks of training, the experimental group experienced an increase of 2.44 mph in throwing velocity which yielded statistically significant results when compared to the comparison group's increase of $0.59 \mathrm{mph}$ which was not statistically significant. The researchers, nonetheless, concluded that exercises using biomechanical principles identified in the SAID principle might prove beneficial to training athletes in overhand throwing sports.
\end{abstract}

Key Words: Plyometric training, youth baseball, throwing velocity. 


\section{Introduction}

The overhand throw is a specialized skill that incorporates numerous biomechanical proficiencies. The velocity of the overhand throw can be a determining factor in the overall mastery and efficiency of the required throwing phases. For many athletes throwing velocity determines their capacity to compete at specific skill levels and can dramatically affect their level of success. As the overall ambition of sports is appearing to shift more and more from the recreational confines of past generations to the professional business demeanor of current day society, ever-increasing pressure may fall upon the shoulders of the young athlete to perform at higher levels. The ability to increase the speed of a thrown ball, (as little as a few miles per hour) may have far greater future ramifications for that individual, apart from the immediate outcome on the game. With this increased emphasis on performance, there becomes a greater value placed on the importance of establishing proper training methods to maximally increase the abilities of the youth athlete.

In reviewing the current literature, little consensus exists as to the most effective methods of training to improve throwing velocity, particularly with respect to the preadolescent athlete. Of the existing research examining training programs to improve throwing velocity, little attention has been given to plyometric training of the upper extremity and its effectiveness in comparison to more traditional strength conditioning programs.

To maximize the effects of a training program, it is believed that the program must be developed to closely resemble the demands placed upon the shoulder complex while performing a throwing motion. Following the principles of specificity, plyometric training is believed to be the mode of exercise, which strongly meets the unique characteristics of this skill and thus should create the greatest likelihood of significantly improving throwing velocity.

\section{Conceptual/Theoretical Framework}

In this study, two relevant concepts were utilized to establish the framework upon which the research question and methodology will be developed, in order to attempt to elicit changes in throwing velocity in a preadolescent population. The first concept is the understanding or belief that the human body can be altered through physical practice or training. If this concept is not accepted, implementing a program that focuses on improving physical attributes would be illogical. The second concept is the SAID principle or Specific Adaptation to Imposed Demands. The SAID principle 
is based on the premise or belief that certain training techniques will provide specific stresses to the particular muscles and joint tissues involved in an action, and therefore elicit an adaptation to the demands placed upon it (Donald A Chu \& Shiner, 2006). Furthermore, exercises should, as closely as possible, represent or reproduce the demands and considerations of the skill being trained in order to allow for adaptations of the precise stresses occurring throughout the application of the skill (Donald A Chu \& Shiner, 2006). Thereby, approximating the parameters of the practiced exercise to the applied skill.

Plyometric training is used to produce powerful movement patterns in fasttwitch muscle fibers. The goal of plyometrics is to load a muscle by a stretch or eccentric contraction followed sequentially by a rapid concentric contraction (Donald Allen Chu, 1998). This concept is an adjunct to the SAID principle, through which it is believed that plyometric training is the most analogous approach that meets the unique demands needed for increasing throwing velocity in the overhead throwing motion.

\section{Specific Adaptations to Imposed Demands Principle/Specificity}

Due to the specificity of training, detailed physiological adaptations have been found to occur in the human body. The following studies indicate how a training program following the SAID principle may have profound adaptations to the skill being trained.

According to Godfrey et al., the mechanism of secreting exercise-induced growth hormone consists of input from the nervous system, direct stimulation by catecholamines, lactate and or nitric oxide, and changes in the acid-base balance (Godfrey, Madgwick, \& Whyte, 2003). In this systematic review, the authors have found evidence that suggests that load and frequency are determining factors in the regulation of $\mathrm{hGH}$ secretion. $\mathrm{hGH}$ is directly related to muscle gains, and when secreted endogenously and naturally within the human body, it is not associated with any pathological side effects contrary to exogenous Hgh (Godfrey et al., 2003). Specifically, the authors have found that the greatest stimulus to the secretion of hGH is achieved when the exercise is performed at an intensity above the lactate threshold for a minimum of 10 minutes. Similarly, plyometrics training is generally performed at a very high-intensity level and at times, above the lactate threshold, hence it is very probable that a plyometric exercise program will elicit secretion of Hgh (Godfrey et al., 2003). 
Nikolaidou et al. (2006) examined any potential relationships between isokinetic, isometric, and dynamic measures of the elbow extensors and flexor muscular strength in volleyball and handball players, mean aged 14-15 yrs. Both of these sports utilize overhand throwing motion. One finding of this study that was of utmost importance was that specializing in an athletic field has an impact on the correlations between the various measures of muscular strength of the elbow extensors and flexors, with respect to the particular muscle mechanics of each throwing activity (Nikolaidou et al., 2006). Handball players have also been found to be stronger compared to volleyball players in the isokinetic and isometric measures of muscular strength of the elbow extensors and flexors. These findings may be considered significant as the arm motion of handball players during overhand throwing is very similar to the one performed by baseball players (Nikolaidou et al., 2006).

\section{Plyometrics}

Literature supports the use of plyometrics and the positive effects of training programs on youth athletes. However, the literature currently contains good amount of studies pertaining to plyometric training for the lower extremity, however only a very few studies on the upper extremity plyometric programs and their effects on overhead throwing velocity. Besides that, the studies that focus on little league baseball players are currently non-existent in the literature. The current literature only studied adults who either compete in professional sports teams or colleges/universities (Carter et al., 2007; McEvoy, Newton, \& Research, 1998).

This form of training has proven to demand greater power in stressed muscle and joint tissues (Baechle \& Earle, 2008). The purpose of plyometric exercise is to increase muscle power and consequently improve performance. It is an exercise type that is designed to elicit a natural high force, high power contraction of muscle fibers, through what is known as the stretch reflex (Wilmore, Costill, \& Kenney, 1994). When muscle fibers become quickly stretched, parallel receptors known as muscle spindles transmit an afferent signal to the spinal cord (Widmaier, Raff, Strang, \& Vander, 2008). This signal is then directly transmitted back to the muscle fibers instead of traveling to higher centers of the CNS (Widmaier et al., 2008). As a result, an immediate contraction of the stretched muscle fibers occurs (Widmaier et al., 2008). Simultaneously, it is believed that inhibitory receptors are known as Golgi Tendon organs, which when forcefully stretched cause muscle deactivation, are disengaged 
allowing for a strong contraction (Baechle \& Earle, 2008). Furthermore, plyometrics have been shown to increase the storage and recoil of muscle fibers, allowing for greater overall force production of the muscle-tendon unit (Finni, Ikegawa, Lepola, \& Komi, 2003). The increased rate of muscle firing along with greater overall production of power by the muscle-tendon unit allows the body to amplify force production (Baechle \& Earle, 2008).

In a study by Davies et al, a plyometric group was tested against a control group to examine the effectiveness of plyometrics over a 6-week training period and significant results were identified in the power production of elbow extensors and shoulder rotators with both isokinetic tests and Closed Kinetic Chain Upper Extremity Stability Tests (Schulte-Edelmann, Davies, Kernozek, \& Gerberding, 2005). Another study by Vissing et al. (2008) compared plyometric training against conventional strength training in countermovement jumping, leg press, knee extension, and knee flexion (Vissing et al., 2008). Although this was a lower-body evaluation there were significant findings to the effect of plyometrics over strength training on muscle power $p<0.05$ (Vissing et al., 2008). Elastic energy, or the energy stored during the cocking phase of throwing, creates importance in teaching athletes to transition from eccentric to concentric movements as fast as possible. Therefore, the delay between the stretch-shorten cycle decreases the reuse of elastic energy (Wilson, Flanagan, \& Research, 2008). During the acceleration phase of throwing, the explosive movement pattern can be enhanced by the increased power output of plyometrics (Wilson et al., 2008). Carter and Kaminski et al. took this theory and over a 6-week session measured the change in throwing velocity for a group of college pitchers as compared to a control group with no plyometric training added to regular strength and conditioning routines (Carter et al., 2007). It was found that the throwing velocity for the intervention group increased an average of $2 \mathrm{mph}$, whereas the control group did not see significant changes. 6 upper extremity plyometric exercises identified as the "Ballistic Six" were used in this intervention (Carter et al., 2007).

Physiologically adaptations occur specific to the demands placed upon the body by the training stimulus (Wilmore et al., 1994). Consequently, the more specific in nature the training stimulus is to the uniqueness of the sporting skills, the greater the training effect will be (Wilmore et al., 1994). In endurance athletes, it has been shown that after a bout of exercise novel genes (mRNA) specific to the recovery period were involved in aerobic adaptations resulting from the exercise bout (Mahoney, Parise, Melov, Safdar, \& Tarnopolsky, 2005). Furthermore, corticospinal 
participation has been shown to be involved in the development of new motor tasks (Schubert et al., 2008). Thereby representing new precise motor learning, and muscle control that is task-specific to the body area being trained (Schubert et al., 2008). Consequently, decreased corticospinal activation has been shown in previously learned tasks (Schubert et al., 2008). Care should then be taken to perform exercises in a manner that closely represents the motor sequencing that is required for the sport-specific task, thereby not influencing separate physiological adaptations that may be contradictory for the unique demands of the skill. The combination of precise genetic adaptations and motor learning behaviors that ensue as a result of a specific training stimulus indicates the importance of the SAID principle.

Plyometric training allows for the active engagement of specific muscles and adaptation to imposed demands as identified by the SAID principle. The emphasis comes in the time and rate of speed from maximal stretch to point of contraction. The progression from fundamental specificity training to training with near maximal resistance, while moving to contraction as fast as possible, improves power and specific movement.

\section{Statement of Purpose}

The purpose of this study was to examine the effects of a 6-week upper-body plyometric training program on throwing velocity in preadolescent male baseball players.

\section{Methods}

This study utilized a quasi-experimental design in which comparisons were made between an upper-extremity plyometric group (UP group) and a comparison group (COMP group). The youth baseball teams used in the study were found by convenience measures, thus allowing randomization only to the six players chosen within each team for participation. With this method, it was expected that the results would provide both interpretable and supportive evidence as to the efficacy of the study's methods.

\section{Setting}

The geographic area of study was concentrated in the Greater Buffalo region of New York State, specifically a suburban town. The general location of the study 
was a field house facility for youth baseball practice and training, as well as a grammar school indoor gym.

\section{Population and Sample}

The target population consisted of youth baseball players, male and aged 1012 years. Only male participants were involved in the study as this was the only accessible population. With the consideration that the sampling would be consistent with a quasi-experimental design, this study employed a convenience sampling system. The convenience sample system was based on two teams, at the target population age, agreed upon to take part in the study. One team served as the experimental group, with 6 randomly assigned members incorporating the study's upper-body plyometric program into their practice regimen, and another team served as the comparison group, consisting of 6 randomly chosen members of the comparison group team, completed their usual practice routine.

\section{Criteria for subject inclusion:}

1. Participant ages were within 10-12 years at time of pre-test.

2. All participants were active team members of their respective leagues.

3. All subjects had completed the general health questionnaire (Appendix $A$ ) without the presence of injuries as noted in the exclusion criteria, or pre-existing health conditions that would have precluded participation in the training program for safety reasons.

\section{Criteria for subject exclusion:}

1. Any participant post-elbow or shoulder surgery within one year of the study's pretest.

2. Any participant presenting with a history of elbow or shoulder injury or pain within one year of the study's pre-test.

3. Any subject answering yes to the questions listed in the General Health Questionnaire.

\section{Human Rights Protection}

Prior to data collection, full approval was obtained from the D'Youville College Institutional Review Board for a Standard Review using human subjects and an experimental design on June $23^{\text {rd }}, 2010$ with the file number $2010 / 36$. Consent 
and Subject Assent was obtained from all subjects prior to entry into the study and all subject data was recorded and maintained in a confidential format. Once data was collected, all information was assigned a code and any identifying information was destroyed by the principal investigators.

\section{Data Collection}

At a pre-season parent/player coaches meeting a script was read describing the purpose, methods, and proposed benefits of participating in the study. Instructions were given to parents regarding home exercise training with participants, and expectations of the exercise frequency and intensities outside of that provided through team activities. Parents and players were provided with consent, assent forms, and a copy of a General Health Questionnaire. All questions about the study were answered by the principal investigators prior to obtaining signed assent and consent. At the conclusion of the meeting, players and parents were asked to place their forms in a dropbox indicating whether they would choose to participate or not, in order to limit subject coercion and maintain confidentiality.

Subjects interested in participating were informed through their coach of the date of baseline data collection. At the time of baseline data collection, subjects in both the control and experimental groups completed demographic questionnaires with information about their height, weight, age, hand dominance, and primary position played at their respective testing session. The instructions were given to the players of the experimental group not to share exercise information with anyone outside of their team.

\section{Baseline Testing and Posttest Data Collection (both groups):}

Data collection for the UP group and COMP group occurred at two separate testing times within the same week, to avoid any threats to internal validity such as compensatory rivalry. Prior to testing, each subject completed a warm-up, to allow for optimal muscle activation, and to avoid injury while performing the test. Upon completion of the warm-up, throwing velocity was measured using a (Sports Radar SR- 3400.) (Address: Sports Radar Ltd., 1760 S Dimensions Terrace, Homosassa, FL 3448). The radar gun was calibrated prior to data collection to ensure valid measures were taken. Subject throwing velocity was tested individually in a batting cage area separated from the warm-up area for the group throwing at the field house facility, and against a pitch back net for the group at the gymnasium. The maximum 
throwing velocity was assessed over a distance of 46 feet (the average distance from a pitching mound to home plate for this age group as specified by the Babe Ruth League Rules and Regulations). Each subject threw from a pitching rubber on flat ground to a net screen target located at the noted distance, with the radar gun placed on a tripod two feet behind the net screen facing the subject. Participants were allowed to take one step before the release of the ball. Upon completion of one throw, the subject was given a 20 second rest period followed by a second throw. This procedure was continued until the participant completed five throws. Each subject completed the testing apart from the rest of the population, thereby maintaining the confidentiality of the testing results. This procedure was repeated 5 times. The top three throws were used to find the average throwing velocity for each participant. Throwing velocity measurements were taken upon initiation and completion of the six-week plyometric program, and each of the three testers was present for both pre-test and post-test.

\section{Group Assignments for Experimental Period:}

After baseline data collection, the comparison group was asked to continue with their usual practice routine for the duration of the 6-week intervention period. The experimental group received instruction in the following intervention.

\section{Plyometric Exercise Design for the UP Group}

The four exercises described for the on-site program were:

1- 2-Handed overhead throw: Start the exercise holding onto a weighted ball with both hands OVERHEAD. Take a single step forward and quickly straighten your elbows to throw the ball to your partner with both hands. Aim at your partner's chest.

2- Handed chest-pass: Hold a weighted ball with both hands at CHEST HEIGHT. Take a single step forward and quickly straighten your elbows and throw the ball to your partner with both hands. Aim at your partner's chest.

3- 90/90 shoulder internal rotation: Set up the theraband to a stable object above and behind where you will be standing. Hold onto the green band with your throwing arm up and straight out to the side and elbow bent to a perfect 90 degrees. From this position quickly snap your forearm forward. Slowly bring your arm back to the starting position and continue.

4- Simulated upper-limb acceleration: Set up the theraband to a stable object above and behind where you will be standing. Hold onto the green band with your 
throwing arm up and back as far as you would if preparing to throw a baseball. From this position quickly make a throwing motion down and across your body while taking one step forward. Slowly return your arm back to the starting position and proceed.

The Principal Investigators (PIs) progressed the program at weeks three and five to ensure exercises were performed at an intensity level necessary to create strength gains within the intervention period (Table 1). The Pls also monitored attendance, compliance, and technique during the 6 week intervention period.

Table 1. Exercise Progression for Practice and Home Exercise Regimen, Experimental Group

\begin{tabular}{|c|c|c|c|c|c|c|c|}
\hline Exercise & Intensity & Repetitions & Sets & Rest & Frequency & & Progression \\
\hline $\begin{array}{l}\text { 2-Handed } \\
\text { overhead } \\
\text { throw }\end{array}$ & $\begin{array}{l}5 \quad \mathrm{ft} \text { or } \\
(\text { theraband } \\
(\text { length }= \\
2.5 \mathrm{ft}) \text { ) }\end{array}$ & 10 & 2 & $\begin{array}{l}\text { Sets: } \quad 15 \\
\text { sec } \\
\text { Sessions: } \\
48 \text { hours }\end{array}$ & $\begin{array}{l}2 \text { x/week } \\
\text { home } \\
\text { exercise } \\
1 / \text { wk }\end{array}$ & + & $\begin{array}{l}\text { Ball throw: Wk } 3 \text { : } \\
7.5 \mathrm{ft} \\
\text { Wk 5: Maximum. } \\
\text { Theraband throw: } \\
\text { Green } 3 \text { wks } \\
\text { Blue } 3 \text { wks }\end{array}$ \\
\hline $\begin{array}{l}\text { 2-Handed } \\
\text { chest-pass } \\
\text { or diamond } \\
\text { push-up }\end{array}$ & $5 \mathrm{ft}$ & 10 & 2 & $\begin{array}{l}\text { Sets: } 15 \\
\text { sec } \\
\text { Sessions: } \\
48 \text { hours }\end{array}$ & $\begin{array}{l}2 \text { x/week } \\
\text { home } \\
\text { exercise } \\
\text { 1x/wk }\end{array}$ & + & $\begin{array}{l}\text { Chest pass: Wk 3: } \\
7.5 \mathrm{ft} \\
\text { Wk 5: Maximum. } \\
\text { Push-up: } \\
\text { Wk 3: table push- } \\
\text { up } \\
\text { Wk 5: floor push-up }\end{array}$ \\
\hline $\begin{array}{l}90 / 90 \\
\text { shoulder } \\
\text { internal } \\
\text { rotation }\end{array}$ & $\begin{array}{l}\text { theraband } \\
\text { (length }= \\
2.5 \mathrm{ft} \text { ) }\end{array}$ & 20 & 2 & $\begin{array}{l}\text { Sets: } 15 \\
\text { sec } \\
\text { Sessions: } \\
48 \text { hours } \\
\end{array}$ & $\begin{array}{l}2 \text { x/week } \\
\text { home } \\
\text { exercise } \\
1 \text { x/wk }\end{array}$ & + & $\begin{array}{l}\text { Progression: green } \\
3 \text { wks } \\
\text { Blue 3wks }\end{array}$ \\
\hline $\begin{array}{l}\text { Simulated } \\
\text { upper-limb } \\
\text { acceleration }\end{array}$ & $\begin{array}{l}\text { theraband } \\
\text { (length }= \\
2.5 \mathrm{ft})\end{array}$ & 20 & 2 & $\begin{array}{l}\text { Sets: } \quad 15 \\
\text { sec } \\
\text { Sessions: } \\
48 \text { hours }\end{array}$ & $\begin{array}{l}2 \text { x/week } \\
\text { home } \\
\text { exercise } \\
1 \text { x/wk }\end{array}$ & + & $\begin{array}{l}\text { Progression: green } \\
\text { 3wks } \\
\text { Blue 3wks }\end{array}$ \\
\hline
\end{tabular}

The three testers were on hand at the practice facility a total of two times during the week of baseline testing, once to collect pre-test data and once to teach the plyometric exercise program to the experimental group. A visit by at least one of the three testers was made each week to teach the expected progressions and carry out exercises with participants. With testers in attendance regularly, proper compliance and technique were monitored during the intervention process, with flexibility for additional exercise demonstrations and visits. At week 7 the final posttest data collection was made. 


\section{Statistical Analysis}

All statistical analyses were conducted using SPSS (version 16.0; Inc., Chicago IL). An independent t-test, a Mann-Whitney test, and two Wilcoxon signed ranks tests were utilized to attempt to identify within, and between, group differences for the variables that were studied. Statistical significance was established prior to analysis at an alpha level of 0.05 indicating that $<0.05$ was indicative of an outcome that would correlate to the interventions $95 \%$ of the time, and leaving only $5 \%$ of the outcomes as occurring due to chance. Wilcoxon signed ranks test were employed within groups from pretest to posttest and independent t-test and the Mann-Whitney tests between experimental and comparison groups (pre and post-intervention).

\section{Baseline Data Analyses: Description of the sample}

A total of twelve male subjects were recruited for this study. The ages of the subjects ranged from 11 to 12 years. Both the experimental and the comparison groups consisted of six subjects each with all the subjects being right-handed and used their right arms for pitching. Both UP and COMP groups were nearly identical in average height prior to the intervention. The UP group had an average height of 1.54 $\mathrm{cm}$ as compared to the COMP group's average height of $1.55 \mathrm{~cm}$. Additionally, the average weight in both groups prior to the intervention did not demonstrate significant differences as the UP group had an average weight of $45.85 \mathrm{~kg}$ as compared to the COMP group's average weight of $45.96 \mathrm{~kg}$. The mean height and weight gain for the UP group post-test intervention were $+1 \mathrm{~cm}$ in height and $+0.38 \mathrm{~kg}$ in weight. Three players in the UP group lost weight, two gained weight and one stayed the same. Five players increased in height while one player stayed the same in the UP group. The COMP group increased its average height by $0.8 \mathrm{~cm}$ and weight by $1.82 \mathrm{~kg}$ postintervention. This data depicts a $1.44 \mathrm{~kg}$ greater increase in average weight in the COMP group post-intervention as compared to the UP group. (Table 2.)

\section{Results}

Table 2. Demographical Data for UP and COMP groups.

\begin{tabular}{lcc}
\hline \multicolumn{1}{c}{ Variables } & Experimental Group & Comparison Group \\
\hline Subjects & 6 & 6 \\
Age & $12 \pm 0.41$ & $12 \pm 0.52$ \\
Pre-test ave weight $(\mathrm{kg})$ & $45.85 \pm 5.92$ & $45.96 \pm 8.00$ \\
Post-test ave weight $(\mathrm{kg})$ & $46.22 \pm 6.54$ & $47.78 \pm 8.87$ \\
Pre-test ave height $(\mathrm{m})$ & $1.54 \pm 0.05$ & $1.57 \pm 0.10$ \\
Post-test ave height $(\mathrm{m})$ & $1.55 \pm 0.05$ & $1.58 \pm 0.10$ \\
Hand Dominance $(\mathrm{R} / \mathrm{L})$ & $\mathrm{R}$ & $\mathrm{R}$ \\
Practice Days & 12 & 12 \\
\hline
\end{tabular}




\section{Throwing Velocity}

An independent t-test revealed a statistically significant difference in throwing velocity between the experimental (UP) and the comparison (COMP) groups preintervention $(p<0.05)$. The mean throwing velocity pre-intervention was $51.8 \mathrm{mph}$ for the UP group, and $55.5 \mathrm{mph}$ for the COMP group (Table 3). This data depicts an average throwing velocity difference of $3.7 \mathrm{mph}$ between the two groups prior to the intervention. A Mann-Whitney test was employed in order to determine the statistical significance of the difference in throwing velocity post-intervention. The MannWhitney test revealed no statistically significant differences in throwing velocities pre to post-test scores between groups ( $p>0.05)$.

Table 3. Comparison of pre-test throwing velocities between UP and COMP groups with corresponding $p$ values and the comparison of differences in pre to post throwing velocities.

\begin{tabular}{lcc|c}
\hline \multicolumn{1}{c}{ Variables } & $\begin{array}{c}\text { Experimental } \\
\text { Group }\end{array}$ & \multicolumn{2}{l}{ Comparison Group } \\
\hline $\begin{array}{l}\text { Pre-test ave throwing velocity } \\
\text { (mph) }\end{array}$ & $51.83 \pm 1.62$ & $55.5 \pm 2.54$ & Pre-test p value \\
$\begin{array}{l}\text { Pre to post test change scores } \\
\text { (mph) Subject 1 }\end{array}$ & 5.33 & -0.67 & 0.013 \\
$\begin{array}{l}\text { Pre to post-test change scores } \\
\text { (mph) Subject 2 }\end{array}$ & 0.67 & 2.33 & \\
$\begin{array}{l}\text { Pre to post-test change scores } \\
\text { (mph) Subject 3 }\end{array}$ & 2.33 & 0.67 & \\
$\begin{array}{l}\text { Pre to post-test change scores } \\
\text { (mph) Subject 4 }\end{array}$ & 2.67 & 0.33 & Post-test p value \\
$\begin{array}{l}\text { Pre to post-test change scores } \\
\text { (mph) Subject 5 }\end{array}$ & 0.67 & 3.33 & 0.092 \\
$\begin{array}{l}\text { Pre to post-test change scores } \\
\text { (mph) Subject 6 }\end{array}$ & 3.00 & -2.33 & \\
\hline
\end{tabular}

A Wilcoxon signed ranks test within the UP group was employed and the test revealed a statistically significant increase in throwing velocity from pre to posttest for the UP group $(p<0.05)$.The UP group experienced a $2.44 \mathrm{mph}$ increase in mean throwing velocity. Another Wilcoxon signed ranks test was utilized within the COMP group, and the test revealed no statistically significant changes in mean velocity from pre to post-test $(\mathrm{p}>0.05)$. The COMP group experienced a $0.59 \mathrm{mph}$ increase in throwing velocity (Table 4, Figure 1). 
Cüre, D., Sterlace, A. \& Griffiths, D. (2020). Implementation of Plyometric Exercises to Improve Throwing Velocity of Male Youth Baseball Players. Gaziantep University Journal of Sport Sciences, 5(3), 310 - 327.

Table 4. Comparison of pre-test and post-test data within UP and COMP groups with corresponding $\mathrm{p}$ values.

\begin{tabular}{|c|c|c|c|c|}
\hline Variables & Exp Group & $\begin{array}{l}\text { P-value UP } \\
\text { group }\end{array}$ & COMP group & $\begin{array}{c}\text { P-value COMP } \\
\text { group }\end{array}$ \\
\hline Subjects & 6 & & 6 & \\
\hline $\begin{array}{l}\text { Pre-test ave throwing } \\
\text { velocity ( } \mathrm{mph} \text { ) }\end{array}$ & $51 \pm 1.62$ & & $55.5 \pm 2.54$ & \\
\hline $\begin{array}{l}\text { Post-test ave throwing } \\
\text { velocity ( } \mathrm{mph})\end{array}$ & $54.28 \pm 1.73$ & 0.03 & $56.11 \pm 4.41$ & 0.52 \\
\hline
\end{tabular}

In summary, both the UP and the COMP groups demonstrated significant differences in the average throwing velocity prior to the intervention. Following two Wilcoxon signed ranks test analyses within each group and an independent t-test comparing change scores between the groups, within the group, however, no statistical differences were noted between the groups. The COMP group did not achieve any statistically significant differences in either within or between groups. The following discussion section will give the readers a more in-depth analysis of the findings of this study.

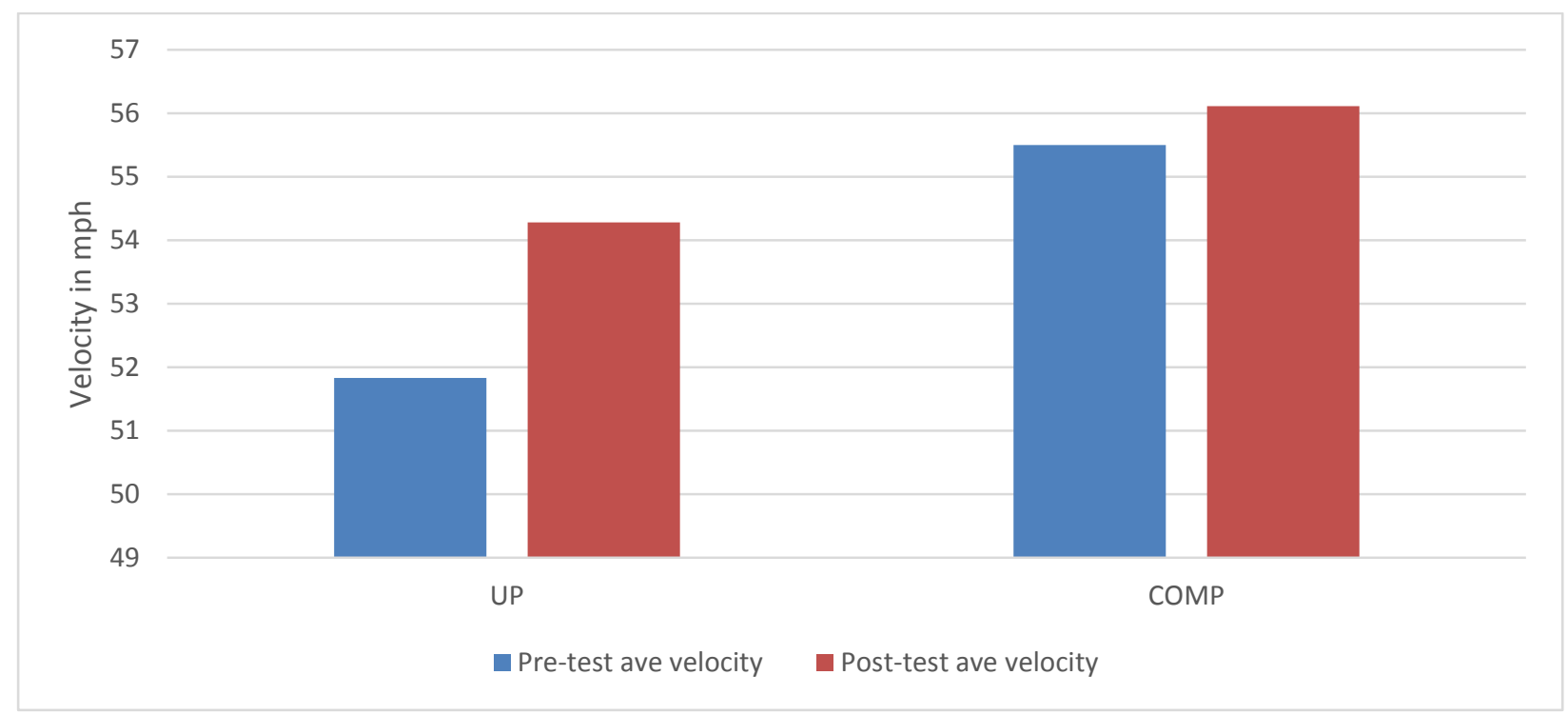

Figure 1. Comparison between UP and COMP groups in terms of differences in average pre-test and post-test velocities 


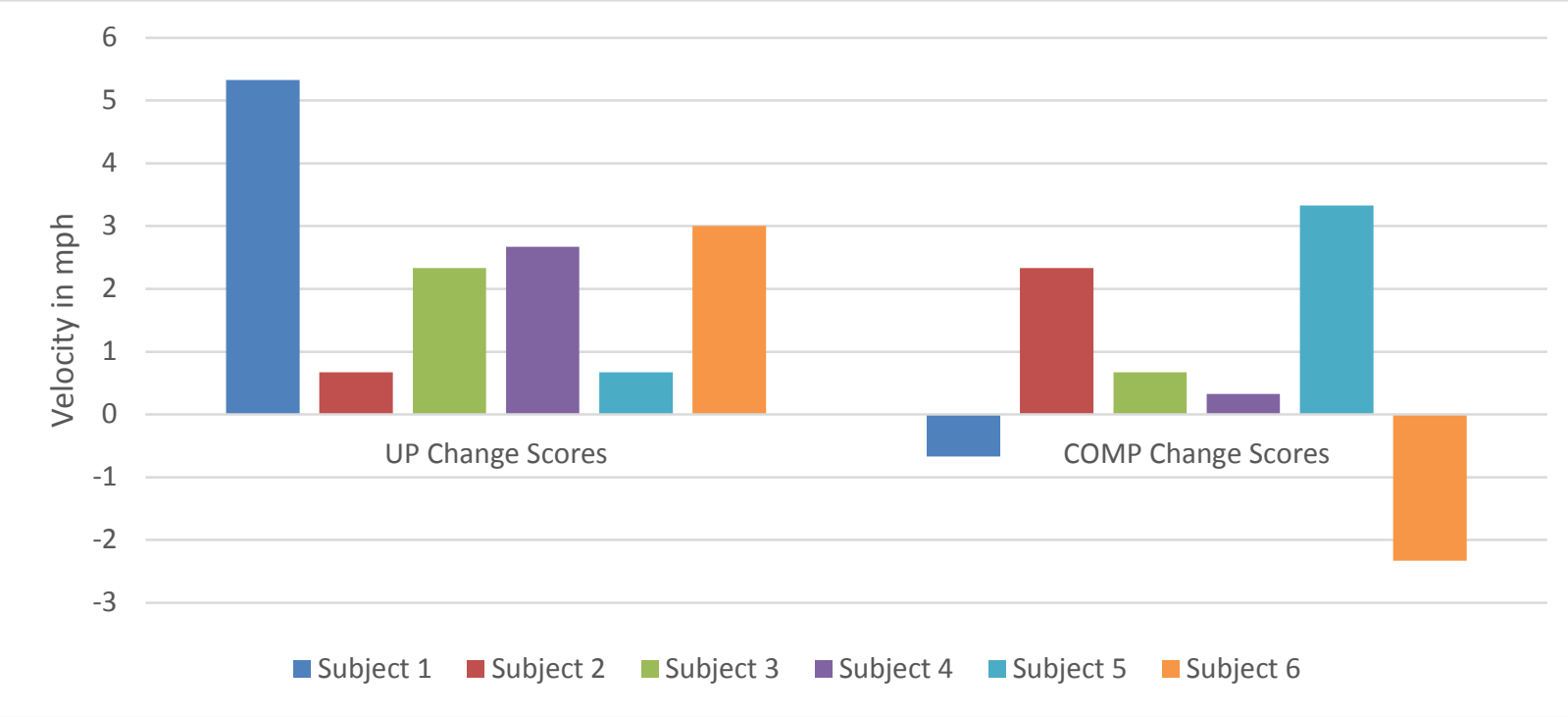

Figure 2. Change score comparison between two groups from pre to postintervention

\section{Discussion}

The outcome of the study was not found to support the authors' hypothesis regarding the effects of specificity training on a functional measure such as throwing velocity when comparing between groups (Table 4). However, a trend toward statistical significance was adequately demonstrated by an overall increase in throwing velocity of $2.44 \mathrm{mph}$ which was found within the UP group from pretest to posttest, as compared to only a $0.59 \mathrm{mph}$ improvement by the COMP group which was not a statistically significant increase. It should be noted that the UP and COMP groups were not found to be statistically equal with pretest measurements (Table 3).

The implications taken from our study are not consistent with what the researchers had expected upon the first hypothesis. Although 12 subjects may suggest a small sample size, and a lack of preexisting research for the efficacy of a plyometric regimen on the upper body in youth athletes, significance was found in the ability to utilize a plyometric program for increasing throwing velocity, as a statistically significant increase was found with in-group analysis. Other studies did not refute or contradict the positive effect of strength or plyometric training on youth individuals, nor did they validate its use for the means used in this study. It is also noted that reliability and compliance, within the constraints of the research design, were closely monitored during on-site activities at each of 11 intervention sessions by at least one member of the experimental research team. Notably, 1 intervention day was monitored by parents to accommodate a cancelled session due to snow. 
The results of the upper plyometric study closely resembled the findings of Carter et al. which utilized an 8-week upper body plyometric program in college baseball players (Carter et al., 2007). Their study used the "Ballistic Six" protocol which includes two very similar exercises to the UP group's program, the overhead soccer throw, and the baseball throw, utilizing the same movement pattern and exercise format as the UP group's 2-handed overhead throw, and simulated upperlimb acceleration (Pretz \& Journal, 2004). Carter et al. found an average increase in throwing velocity of $2.0 \mathrm{mph}$ in their plyometric group, with an average increase of only $0.27 \mathrm{mph}$ in their control group, of which the UP group's results strongly correspond (2.44 $\mathrm{mph}$ and $0.59 \mathrm{mph}$ respectively) (Carter et al., 2007). As both training programs take into consideration the SAID (specific adaptations to imposed demands) philosophy, it may be noted that improvements in throwing velocity are directly correlated with increasing the training demands on the body in ways that closely simulate the throwing motion. Although no testing was performed to identify possible neuro-physiological effects of the plyometric program on the subjects, the results of our study and the closely related findings of Carter et al. help to validate the concept that athletic skills should be trained in a way which mimics the desired motion (Carter et al., 2007).

When analyzing pre to post-test data within a group, an upper-body plyometric training program can significantly increase throwing velocity in youth male baseball players as evidenced by an average increase of $2.44 \mathrm{mph}$. These results are similar to a study by Davies et al. and a study by Vissing et al., demonstrating that a 6 -week plyometric program significantly increased elbow extensor and rotator cuff power production and that power output can be trained more effectively with plyometric training when compared to traditional strength training, respectively (SchulteEdelmann et al., 2005; Vissing et al., 2008). The problem with making an inference from the Davies and Vissing studies is that no definite cause and effect relationship can be stated, as this study did not measure those variables. Instead, it is only hypothesized by the researchers that the strength and power gains were made as evidenced by improvements in the functional outcome of throwing velocity ranging from $0.66 \mathrm{mph}$ to $5.35 \mathrm{mph}$ for an average increase of $2.44 \mathrm{mph}$ for the UP group. The same could not be concluded for the COMP group as post-test scores ranged from a loss of $2.33 \mathrm{mph}$ to a gain of $3.33 \mathrm{mph}$, for an average but not a significant increase of $0.59 \mathrm{mph}$. 
The researchers, nonetheless, concluded that exercises using biomechanical principles identified in the SAID principle might prove beneficial to training athletes in overhand throwing sports. A concurrent study run with a separate group of experimental subjects during the same 6-week study period focused its efforts at finding a possible significance between interventions of the body's core strength on throwing velocity. The core strength group's intervention was not found to be as effective an intervention for improving the very specific task of throwing, indicated by a $1.11 \mathrm{mph}$ difference in increase when comparing the UP group's results to the core strength group's results. This leads us to believe that this study was a necessary pilot study to provide results for the sport of such specificity training in preadolescents worldwide.

\section{Future Recommendations}

Future studies should investigate the power output of the major upper extremity muscles involved in the throwing motion, and likewise examine how training of all the muscles specific to that motion might increase muscle output and throwing velocity as a result. However, this study did not incorporate this into its content and, consequently, the results of this research cannot identify the mechanism responsible for the improvements found within the subjects. Therefore, future research is warranted to examine the exact physiologic and/or neurophysiological responses of an upper-body plyometric program on the throwing extremity of youth baseball players. It is also a consideration to focus exercise on fatigue provoking intensity for the four exercises utilized thereby ensuring maximal adaptation equal to all subjects. Future studies should also investigate whether or not this type of a plyometrics exercise program prevents injuries in this specific population.

\section{Limitations of the study}

The assumptions and limitations inherent in the study provide a possible argument for a lack of significant representation as only 6 subjects were included in the intervention of this study. Questions on compliance and efficacy in the controlled setting, versus effectiveness in real-life application, also limit the overall design of this research. The researchers took measures to prevent such realities by instituting a certified Sports Radar machine for reliability in data, data logs, and supervision for tracking a maximal effort and adherence and limiting obstacles to the representation of expected inclusion criteria. However, overflow from other activities, training 
adaptations from other practice-related drills, and cross-training with other sports could not be distinguished and may have skewed true representation of expected gains. Moreover, communication between teams on study parameters and interventions posed threats to external validity throughout the six-week process. For instance, there were no means to monitor restrictions on subjects from the UP and COMP group from comparing intervention strategies with each other. As both groups were living in the same area and likely participating in numerous social and recreational activities together, the COMP group could have, through interaction, learned about the intervention strategies from the UP group and incorporated them into their individual training program.

\section{Conclusion}

The research results were not found to confirm the hypothesis of the authors concerning the effects of specificity training (Table 4). A trend towards statistical significance, however, was sufficiently illustrated by an overall rise in the throwing velocity of $2.44 \mathrm{mph}$ found within the UP group from pretest to posttest, compared to only a $0.59 \mathrm{mph}$ gain by the COMP group which was not a statistically significant change.

\section{References}

Baechle, T. R., \& Earle, R. W. (2008). Essentials of strength training and conditioning: Human kinetics.

Carter, A. B., Kaminski, T. W., Douex Jr, A. T., Knight, C. A., Richards, J. G. J. T. J. o. S., \& Research, C. (2007). Effects of high volume upper extremity plyometric training on throwing velocity and functional strength ratios of the shoulder rotators in collegiate baseball players. 21(1), 208-215.

Chu, D. A. (1998). Jumping into plyometrics: Human Kinetics.

Chu, D. A., \& Shiner, J. J. S. s. r. R. D., ed. St Louis, MO: Churchill Livingstone Elsevier. (2006). Plyometrics in rehabilitation. 233-246.

Finni, T., Ikegawa, S., Lepola, V., \& Komi, P. J. A. P. S. (2003). Comparison of forcevelocity relationships of vastus lateralis muscle in isokinetic and in stretchshortening cycle exercises. 177(4), 483-491.

Godfrey, R. J., Madgwick, Z., \& Whyte, G. P. J. S. m. (2003). The exercise-induced growth hormone response in athletes. 33(8), 599-613.

Mahoney, D., Parise, G., Melov, S., Safdar, A., \& Tarnopolsky, M. J. T. F. j. (2005). Analysis of global mRNA expression in human skeletal muscle during recovery from endurance exercise. 19(11), 1498-1500.

McEvoy, K. P., Newton, R. U. J. T. J. o. S., \& Research, C. (1998). Baseball throwing speed and base running speed: The effects of ballistic resistance training. 12(4), 216-221. 
Nikolaidou, M.-E., Rousanoglou, E. N., Bayios, I. A., Boudolos, K. D. J. I., \& science, e. (2006). Athletic specialization of young males and relationships of elbow extensor and flexor muscular strength. 14(4), 307-315.

Pretz, R. J. S., \& Journal, C. (2004). " Ballistic Six" Plyometric Training for the Overhead Throwing Athlete. 26(6), 62.

Schubert, M., Beck, S., Taube, W., Amtage, F., Faist, M., \& Gruber, M. J. E. J. o. N. (2008). Balance training and ballistic strength training are associated with task-specific corticospinal adaptations. 27(8), 2007-2018.

Schulte-Edelmann, J. A., Davies, G. J., Kernozek, T. W., \& Gerberding, E. D. J. J. S. C. R. (2005). The effects of plyometric training of the posterior shoulder and elbow. 19(1), 129-134.

Vissing, K., Brink, M., Lønbro, S., Sørensen, H., Overgaard, K., Danborg, K., . . . Research, C. (2008). Muscle adaptations to plyometric vs. resistance training in untrained young men. 22(6), 1799-1810.

Widmaier, E. P., Raff, H., Strang, K. T., \& Vander, A. J. (2008). Vander's Human physiology: the mechanisms of body function: Boston: McGraw-Hill Higher Education.

Wilmore, J. H., Costill, D. L., \& Kenney, W. L. (1994). Physiology of sport and exercise (Vol. 524): Human kinetics Champaign, IL.

Wilson, J. M., Flanagan, E. P. J. T. J. o. S., \& Research, C. (2008). The role of elastic energy in activities with high force and power requirements: a brief review. 22(5), 1705-1715. 